\title{
Pharmacological Management of Adults with Chronic Non-Cancer Pain in General Practice
}

\author{
Cesare Bonezzi · Diego Fornasari · Claudio Cricelli · Alberto Magni · \\ Giuseppe Ventriglia
}

Received: July 27, 2020 / Accepted: November 4, 2020 / Published online: December 11, 2020

(C) The Author(s) 2020

\begin{abstract}
Chronic pain is a public health priority that affects about $20 \%$ of the general population, causing disability and impacting productivity and quality of life. It is often managed in the primary care setting. Chronic pain management is most effective when the pain mechanism has been identified and addressed by appropriate therapy. This document provides an overview of pharmacological therapy for chronic noncancer pain in the primary care setting, with the
\end{abstract}

C. Bonezzi

ICS Maugeri IRCCS, Via Salvatore Maugeri 10, Pavia, Italy

D. Fornasari $(\varangle)$

Department of Medical Biotechnology and

Translational Medicine, Università Degli Studi Di

Milano, Via Vanvitelli 32, Milan, Italy

e-mail: diego.fornasari@unimi.it

C. Cricelli · A. Magni · G. Ventriglia

SIMG (Italian College of General Practitioners and Primary Care), Via Del Sansovino 179, Florence, Italy aim of improving treatment decisions based on the underlying pain mechanisms and pain neuroscience.

Keywords: Chronic pain; Management; Primary care; Therapy

\section{Key Summary Points}

This article covers pharmacological therapy for chronic non-cancer pain in the primary care setting, where many patients with this condition present.

The accompanying article describes a pathway for identifying the underlying mechanism causing chronic pain, the "pain generator".

Pain may be mechanical nociceptive, inflammatory nociceptive (with or without significant spinal sensitization), neuropathic, or mixed pain.

Basing treatment decisions on the underlying pain mechanism and on pain neuroscience ensures that patients with chronic pain receive the best possible care, which may require referral to a pain specialist. 


\section{DIGITAL FEATURES}

This article is published with digital features, including a summary slide, to facilitate understanding of the article. To view digital features for this article, go to https://doi.org/10.6084/ m9.figshare.13182854.

\section{INTRODUCTION}

Chronic non-cancer pain affects about $20 \%$ of the population and represents one of the most frequent conditions presenting in general practice. Despite this high prevalence and the associated burden for patients and society, it is often treated inadequately $[1,2]$. Management represents a challenge due to its prevalence and complexity. It can be nociceptive, neuropathic, or mixed pain that persists after an injury has healed or is associated with an ongoing chronic condition. Central pain modulation is altered in a subset of patients, resulting in central sensitization [3].

Lack of training in pain medicine among healthcare professionals can hinder optimal management of chronic pain [4-6]. Effective pain management requires identification of the type of pain (Box 1) and underlying mechanism, as described in the accompanying article [7]. Once the pain generator is identified, a therapeutic approach appropriate for the nature and severity of the pain can be applied. Treatment decisions must respect patient preferences and consider the patient's medical status, contraindications to specific therapies, or comorbidities that could increase the risk of side effects. The first-line treatment for many types of chronic pain includes exercise and psychosocial education. Effective management may require multimodal treatment and/or titration to higher doses or more effective therapies.

The present article covers pharmacological therapy for chronic non-cancer pain in the primary care setting with the aim of improving treatment decisions based on the underlying pain mechanisms and pain neuroscience.

This article is based on previously conducted studies and does not contain any new studies with human participants or animals performed by any of the authors.

\section{BOX 1. MAJOR PAIN TYPES}

Nociceptive pain-pain that results from stimulation and firing of pain receptors on somatic nerve fibers associated with a chemical, mechanical, or thermal insult.

Neuropathic pain-Neuropathic pain-pain that results from a lesion or disease of the central or peripheral nervous system. It is characterized by both positive symptoms (such as paraesthesia, dysaesthesia, burning, sensation of electric discharge, involving pain from ectopic firing evoked by mechanical, thermal, inflammatory or ischemic factors) and negative symptoms (sensory deficits) that have a "neuroanatomically plausible" distribution.

Mixed pain-pain that results from partial lesion of a nerve fiber, such that ectopic firing produces positive symptoms with a "neuroanatomically plausible" distribution in the absence of sensory deficits. "Mixed" because inflammation of surrounding tissues evokes the ectopic firing.

Central sensitization-amplification of pain signal transmission due to altered pain modulation that causes expansion of the area where pain is perceived and pain hypersensitivity (hyperalgesia and secondary allodynia).

\section{MANAGEMENT}

\section{Drugs Acting on Peripheral Sensitization}

Corticosteroids are powerful anti-inflammatory agents that inhibit the expression of genes encoding a host of proinflammatory factors, including cytokines and chemokines, receptors, adhesion molecules and enzymes, including cyclooxygenase-2 (COX-2). Expression of these genes is activated by proinflammatory transcription factors, in particular nuclear factor- $\kappa \mathrm{B}$ 


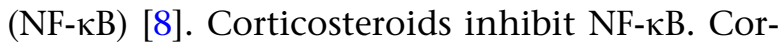
ticosteroids do not appear to influence the expression of COX-2 in endothelial cells, where expression is controlled by blood fluid mechanical stimuli [9]. Agents that inhibit COX-2 in endothelial cells are associated with increased cardiovascular risk. Therefore, corticosteroids may have lower risk for cardiovascular events in the patient with ischemic risk; nevertheless, they are associated with a risk of metabolic decompensation and could be detrimental in patients with heart failure.

Nonsteroidal anti-inflammatory drugs (NSAIDs) block the production of prostanoids, by inhibiting cyclooxygenase enzymes 1 and/or 2 (COX-1, COX-2) [10]. COX-1 is expressed constitutively in many tissues including gastric mucosa where it produces cytoprotective prostaglandins. In immune system cells, COX-2 is not expressed constitutively, but is induced in inflamed tissues, where it produces prostaglandins that lower the pain threshold of sensory neurons, causing hyperalgesia. COX inhibitors are distinguished by their isozyme selectivity, which can be expressed as the ratio of their $\mathrm{IC}_{50}$ for $\mathrm{COX}-1 /$ $\mathrm{IC}_{50}$ for COX-2 (Fig. 1). COX inhibitors reduce

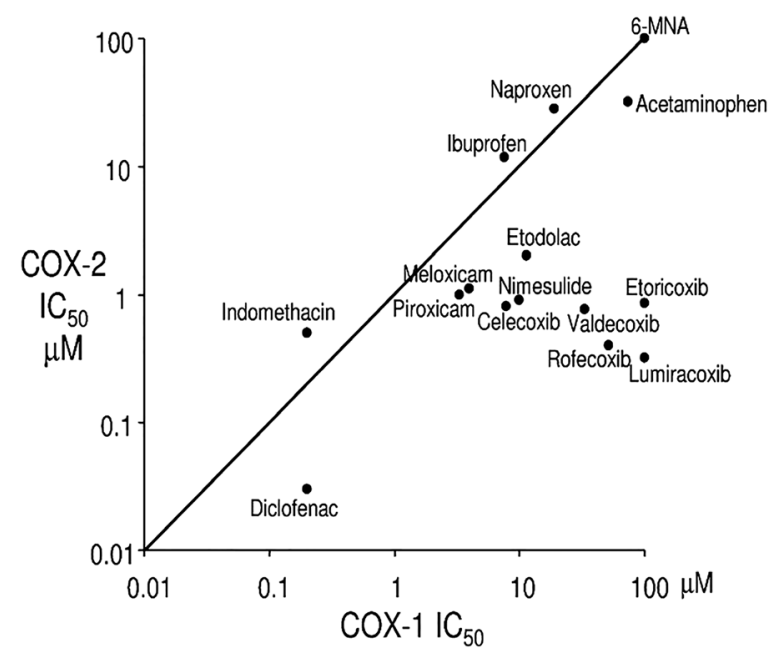

Fig. 1 Potency of NSAIDs in inhibiting COX-1 and COX-2 enzymes. Concentrations required to inhibit the activity of cyclooxygenase-1 (COX-1) and cyclooxygenase2 (COX-2) by $50 \%$ (IC50). Reproduced with permission from figure from Patrignani P, Patrono C. Cyclooxygenase inhibitors: From pharmacology to clinical read-outs. Biochim Biophys Acta. 2015;1851(4):422-32 inflammation, fever, and pain, but also reduce the production of prostacyclin (PGi) in endothelial cells. PGi is a potent antiplatelet molecule that counteracts the action of thromboxane A2 (TXA2) and plays an essential antithrombotic role. Thus, all NSAIDs, with the possible exception of acetylsalicylate, can potentially increase ischemic cardiovascular risk. On the other hand, non-selective COX inhibitors block the activity of gastric COX-1, which is responsible for producing the prostanoids that stimulate bicarbonate and mucus production, thereby increasing the risk of GI lesions.

COX-2 inhibition and pain-COX-2 is a key player in inflammation and pain and agents that target it are first-level drugs for inflammatory nociceptive pain. The main pharmacological determinant among their antiinflammatory and analgesic properties is not their selectivity, which mainly relates to adverse gastric events, but their COX-2 inhibition. Indeed, diclofenac, a non-selective COX-2 inhibitor, has the greatest activity not only for reducing pain but also for improving levels of physical functioning [11]. NSAIDs are available in a variety of formulations including immediate acting and prolonged release formulations that allow once daily administration.

\section{Drugs Acting on Nerve Fibers}

In neuropathic pain, damage to nerve fibers causes an increase in the number and type of sodium channels in the lesioned fiber, accompanied by a lower discharge threshold, enhanced response, and spontaneous ectopic discharges [12]. This condition increases the number of presynaptic calcium channels on neurons in the injured fiber, increasing excitability and the release of neurotransmitters [13]. Moreover, inhibitory systems are less active, contributing to increased excitability of the second neuron, which may also undergo receptor modifications. These events make neuropathic pain difficult to control. Therapies with drugs that work on these targets, such as the gabapentinoids and tricyclic antidepressants, may improve outcomes. Neuropathic pain can result from several non-mutually 
exclusive mechanisms. A better understanding of the underlying pathophysiological mechanisms may facilitate further stratification of patients and tailoring of treatment to their specific conditions $[14,15]$. Uncontrolled neuropathic pain should be referred to a pain specialist, especially if pain is severe, substantially limits daily activities, or when underlying health conditions have deteriorated [16].

\section{Drugs Blocking Voltage-Gated Sodium Channel}

The blockade of voltage-gated sodium channels interferes with the propagation of action potentials along nociceptive fibers. Their use is especially indicated in neuropathic pain, in which high-frequency ectopic discharges originate from the lesioned fibers. These drugs generally belong to anticonvulsant or antiarrhythmic therapeutic classes and include carbamazepine, oxcarbazepine, or lidocaine [17]. Carbamazepine is indicated in trigeminal pain. The rapid release formulation $200 \mathrm{mg}$ bid should be used. When discontinuing therapy, patients should gradually reduce their dosage to reduce the risk of withdrawal symptoms. Lidocaine is available as a transdermal patch that is indicated for post-herpetic neuralgia [18].

\section{Drugs Acting on Voltage-Gated Calcium Channels}

Voltage-gated calcium channels are widely distributed in the CNS. In the dorsal horn of the spinal cord, they are localized on the presynaptic terminal of the afferent fibers, where they control synaptic glutamate release, that in turn activates second-order neurons. They contain an accessory $\alpha 2 \delta$ subunit that anchors the channel to the extracellular matrix and regulates receptor turnover [19]. Normal turnover involves internalization of receptors from the plasma membrane and insertion of new molecules from inside the cell. In neuropathic pain, modification of the extracellular matrix prevents the normal internalization and removal of channels from the plasma membrane; their subsequent accumulation causes aberrant release of glutamate.

Gabapentinoids, also known as $\alpha 2 \delta$ ligands, promote the internalization of calcium channels by binding to their accessory $\alpha 2 \delta$ subunits [20]. Therefore, these drugs act, not by directly inhibiting voltage-gated calcium channels, but by normalizing calcium channel turnover [21]. By reducing channel accumulation on the plasma membrane, they reduce the spinal hyperexcitability that occurs, for example, in diabetic neuropathy. Their effect requires time to develop and must be tapered at discontinuation. The most common agents are gabapentin and pregabalin. These are not metabolized and undergo renal elimination. Side effects may be apparent at high doses, and a recent Drug Safety Communication from the US FDA warns about serious breathing problems when administered with CNS depressants or in patients with lung problems [22]. Mirogabalin, an emerging $\alpha 2 \delta$ ligand approved in Japan for neuropathic pain, has increased selectivity and slower dissociation rates for the $\alpha_{2} \delta$-1 subunit compared to the $\alpha_{2} \delta$-2 subunit, which may lead to fewer central nervous system adverse effects and increased analgesic potency [23].

Gabapentinoids are not used for nociceptive pain, because there is no accumulation of calcium channels. Regarding mixed pain, theoretically they could be used to address the neuropathic component; however, targeting the stimulatory inflammatory factors in mixed pain is often more effective.

\section{Drugs Affecting Spinal Transmission and Central Sensitization}

Paracetamol has antipyretic and analgesic effects but is not an anti-inflammatory agent. It has only central analgesic effects mediated by its active metabolite $\mathrm{N}$-arachidonoyl-phenolamine (AM404), which forms in the CNS and acts as an anandamide reuptake inhibitor in the dorsal horn of the spinal cord [24]. It should be considered a first-level agent for reducing pain transmission at the spinal level. Intravenous administration provides more effective analgesia because it rapidly achieves high CNS levels 
of AM404 [25]. Paracetamol is indicated in monotherapy in the absence of significant inflammation, such as in noninflammatory muscle fatigue pain; otherwise, it should be administered in combination with an anti-inflammatory; fixed-dose combinations are available. It is not effective for primary (inflammatory) allodynia but may relive secondary allodynia (central sensitization). Combinations with opioids benefit in terms of improved tolerability from the antiemetic cannabinoid effect provided by AM404 [26].

Benzodiazepines enhance the activity of the inhibitory neurotransmitter gamma-aminobutyric acid (GABA). Benzodiazepines are not indicated in pain management; however, clonazepam is efficacious in some patients with central sensitization [27], for which it has been used off-label.

Opioids are very effective central analgesics. Opioid receptors are inhibitory G protein-coupled receptors (GPCRs) for endogenous opioids [28]. The opioids commonly used in pain management act at $\mu$-opioid receptors, which are present at high concentrations in areas at the interface between the ascending pain pathway and descending inhibitory pathway (the superficial dorsal horn of the spinal cord, periaqueductal gray, locus coeruleus, rostral ventromedial medulla). On the presynaptic afferent terminals of sensory neurons, $\mu$-opioid receptor activation blocks voltage-gated calcium channels, inhibiting the release of excitatory neurotransmitters and blocking transmission, whereas on postsynaptic secondary neurons it opens potassium channels, causing hyperpolarization and reducing neuronal excitability [29]. Therefore, by analogy, it renders the afferent sensory neuron mute and the secondorder neuron deaf.

Given their important side effects, they should be administered following established criteria, for example the CDC checklist for prescribing opioids for chronic pain [30]. They can be administered as immediate-release (shortacting) formulations that have relatively rapid onset and a short duration of effect that is essential during the initial trial period (titration). Patents should be reassessed after 3 days to determine response and tolerability.
Common side effects include constipation, drowsiness, and confusion.

Individual differences exist among patients in their propensity to develop tolerance, sensitization, or hyperalgesia with opioids [31]. The rate of opioid metabolism (CYP3A4 and CYP2D6) can also vary widely, with important impact on their effectiveness [32]. To reduce opioid-induced constipation, they may be combined with oral administration of the competitive opioid receptor antagonist naloxone, which blocks opioid receptors in the intestine but is subject to extensive hepatic firstpass metabolism [33].

Dual-acting opioid analgesics are weak $\mu$-opioid receptor agonists that also increase central synaptic monoamine neurotransmitter levels [34]. Tramadol is a weak $\mu$-opioid receptor agonist that also inhibits serotonin and norepinephrine reuptake [35]. Its activity on opioid receptors is attributed to the major active metabolite desmethyltramadol. Tapentadol is another opioid analgesic with a dual mode of action, working both as an opioid receptor agonist and as a norepinephrine reuptake inhibitor [36], with little effect on serotonin reuptake [37]. Its activity on opioid receptors is attributed to the parent molecule, therefore metabolism is not required (i.e., it is not a prodrug). Both drugs have a rapid onset of activity.

\section{Drugs Acting on the Inhibitory Descending Pathways}

Antidepressants (tricyclic antidepressants and serotonin noradrenaline reuptake inhibitors) are often used to treat chronic pain [38, 39]. Amitriptyline is a tricyclic serotonin and noradrenalin reuptake inhibitor that potentiates the descending inhibitory pathway and blocks sodium channels, making it effective for neuropathic pain. It has a rapid effect on pain, especially when an immediate release formulation is used. Dosages below the standard $25 \mathrm{mg}$ can be effective for pain. Several partially selective serotonin and norepinephrine reuptake inhibitors (e.g., duloxetine, venlafaxine, desvenlafaxine) are also used for neuropathic pain [40]. When administered at low doses, 
these agents are somewhat selective for serotonin, whereas at high doses they inhibit also norepinephrine reuptake.

Acetyl-l-carnitine-Metabotropic glutamate receptors 2 (mGluR2) are expressed on the presynaptic membrane of the afferent nociceptive fibers in the spinal cord. They are activated by glutamate released from the same fiber on which they are expressed (autoreceptors) and block voltage-gated calcium channel, thus reducing further glutamate release through negative feedback. They may be considered a physiological "brake" to control spinal synapse activity [41]. Acetyl-L-carnitine increases mGluR2 expression through an epigenetic effect on mGluR2 gene transcription [42]. The epigenetic effect has a slow onset; therefore, to enhance the effect, acetyl-L-carnitine is initially administered via intramuscular injections for 10 days to bypass hepatic de-acetylation [43]; this is followed by oral maintenance therapy. The effect is long lasting, even after administration is stopped [44]. It is generally administered in combination with other agents. In addition to its analgesic effect, it has neurotrophic and neuroprotective effects.

\section{Drugs Acting on Muscle Contraction}

Skeletal muscles are widely innervated by nociceptive fibers that are specialized in sensing low $\mathrm{pH}$ (i.e., acidosis). Protons that accumulate during muscular activity can directly stimulate acid-sensing ion channels (ASICs) causing pain [45]. In muscle contracture, sustained contraction provokes ischemia, which causes low tissue $\mathrm{pH}$ and provokes pain, even in the absence of inflammation.

\section{Skeletal Muscle Relaxants}

Myofascial trigger points-a limited area of contracted ischemic muscle that is painful to

\section{DRUGS ACTING AT THE SYNAPSE}

I. Modulating action with or without spinal sensitization:

paracetamol - opioids - acetyl-L-carnitine

II. Neuropathic pain:

Alpha2 Delta ligands (gabapentin, pregabalin) - clonazepam

III. Indirect modulatory action mediated by the spinal or descending inhibitory system: tricyclics, duloxetine, venlafaxine

IV. Actions I + III: tramadol, tapentadol

\section{ANALGESICS}

ACTING ON RECEPTORS

Corticosteroids, NSAIDs, Selective Cox-2 inhibitors

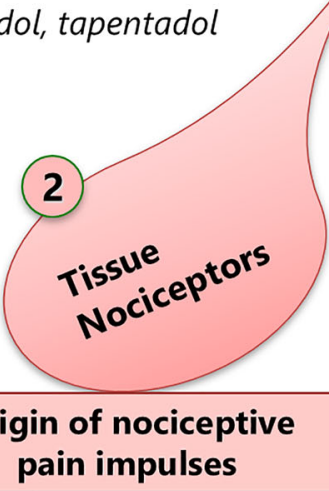

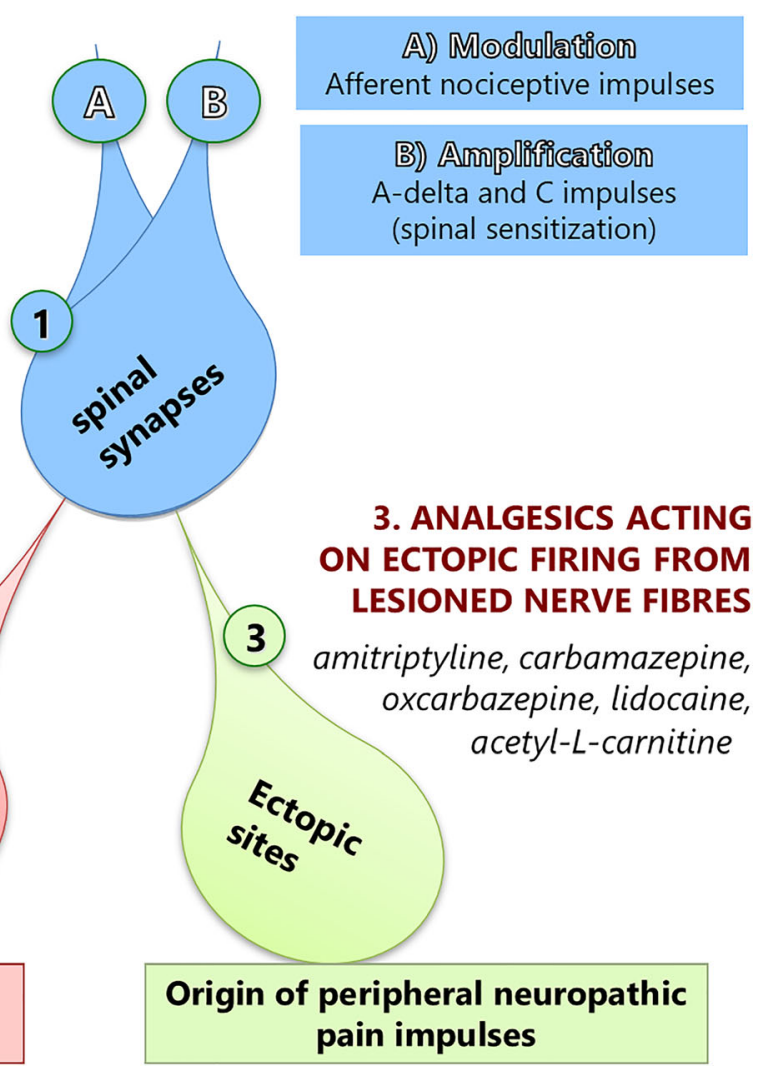

Fig. 2 Analgesics and pathogenetic mechanisms 
touch or press and provokes both local and referred pain. This area of ischemia has low $\mathrm{pH}$ that maintains the contraction in a vicious cycle. Anti-inflammatory drugs have no effect on this phenomenon. Often mistaken for other conditions, trigger points may respond to strong mechanical manipulation or dry needling [46].

For extensive muscle contracture, muscle relaxation should always be carried out to relieve the ischemia. Contraction is provoked by discharge of both alpha and gamma motor neurons. In a recent review, muscle relaxants have proven clinically significant pain relief compared with placebo for acute low back pain [47]. In addition, the ACP guidelines recommend them as the first pharmacological line together with NSAIDs [48]. There is no level I evidence supporting the efficacy of benzodiazepines in people with low back pain [47], but they can be effective for some severe muscle spasms, for which they must be administered intramuscularly.
Tizanidine, an imidazoline derivative, is a central-acting noradrenergic alpha-2 receptor agonist that blocks the release of excitatory amino acids like glutamate and aspartate from spinal interneurons and increases presynaptic inhibition of motor neurons with the greatest effect on spinal polysynaptic pathways [49]. The overall effect of these actions is thought to reduce the facilitation of spinal motor neurons.

Eperisone relaxes skeletal muscles by reducing muscle spindle sensitivity via $\gamma$-motor neurons; furthermore, it antagonizes calcium channels on vascular smooth muscle cells, increasing blood flow in the contracted muscles and improving oxygenation, and has muscular sympatholytic actions. Eperisone also blocks voltage-dependent sodium channels on the nerve fibers, providing an antinociceptive effect. It is associated with a lower incidence of sedation than tizanidine [50].

Thiocolchicoside is another widely used muscle relaxant. Its mechanism of action is highly controversial. Molecular studies have shown that it antagonizes GABAa and glycine

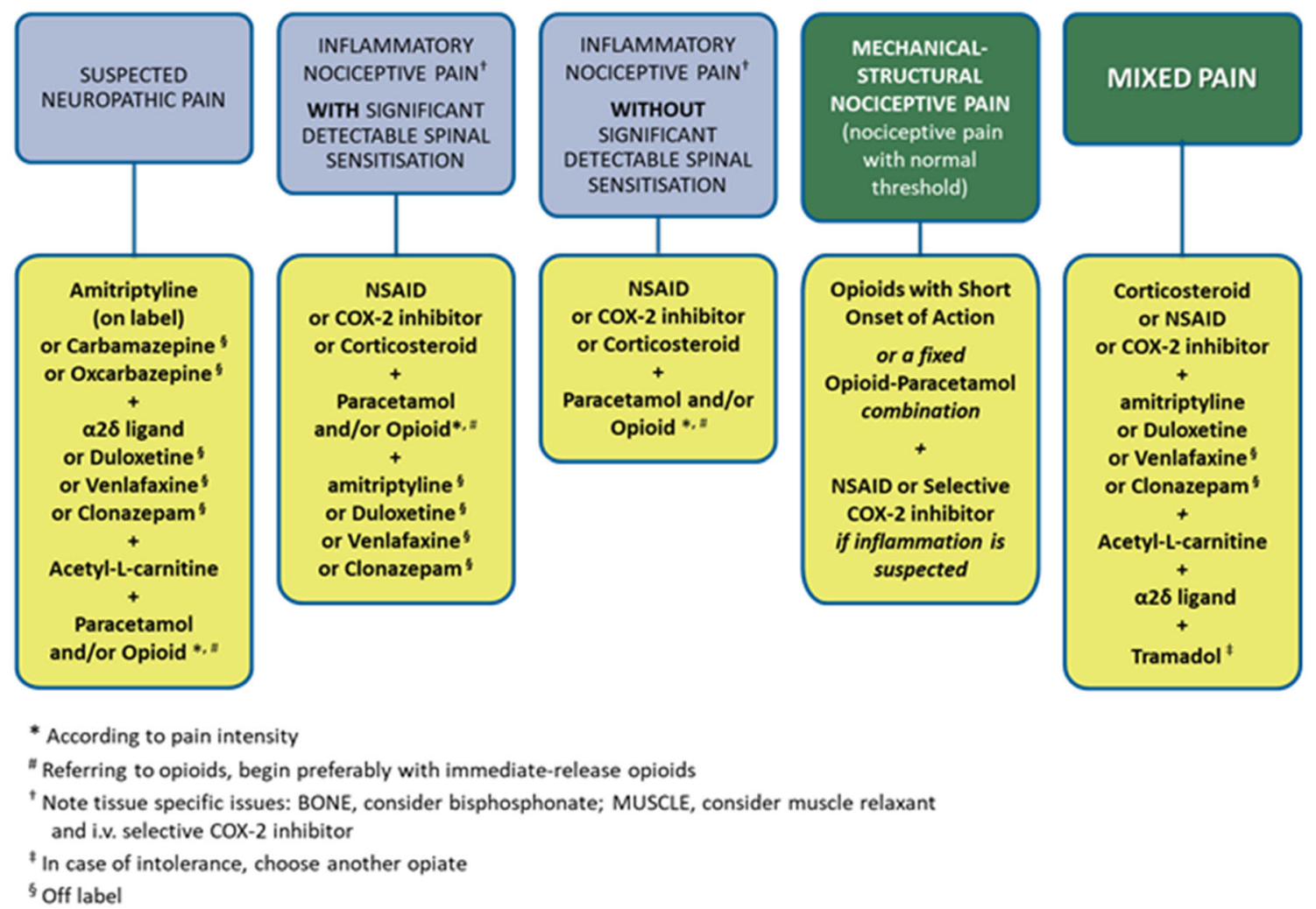

Fig. 3 Pain type and multimodal therapy: criteria for choosing and list of appropriate drug therapies 
receptors, giving it a pharmacodynamic profile that is exactly the opposite of what is expected for a muscle relaxant [51]. One pharmacological hypothesis to explain the muscle relaxant effect is that thiocolchicoside may act at the supraspinal level, through an unknown mechanism. It must be administered with caution, because it is neurotoxic and teratogenic [52]. Its use is restricted to low-dose therapy of short duration for painful muscle contractures [53].

\section{Combination Therapy}

Polypharmacy is justified by the complex nature of pain. For example, the therapeutic targets in neuropathic pain include suppressing external mechanical, inflammatory, and/or ischemic stimuli, blocking sodium channels, normalizing calcium channel numbers, and potentiating the descending inhibitory pathway. When administering more than one therapy, drugs with different mechanisms of action should be used. The use of combinations allows lower drug doses, which may reduce the incidence of dosedependent side effects. Consider the benefits and risks of each drug. Titrate their dosages to achieve pain relief while minimizing side effects. Monitor efficacy and side effects and allow appropriate time for response to develop, especially for neuropathic pain.

\section{APPLICATIONS}

Choose the analgesic strategy based on the pain type and severity, combined with a thorough assessment of comorbidities and other medications that the patient is receiving. Assess whether sensitization is present. Peripheral sensitization is present when normally painless contact (primary allodynia) within the painful area causes discomfort or pain; spinal sensitization (secondary allodynia) is present when gentle brush strokes in and adjacent to the painful area provoke discomfort or pain [7]. See Fig. 2 for a summary of pain mechanisms and corresponding treatment strategies. Figure 3 provides a list of appropriate treatments according to pain type. The choice of drug and dosage must be based on the severity and type of pain.

Figure 4 outlines treatment courses according to pain type. In principle, the treatments are organized stepwise from non-opioid analgesics through weak opioids and finally strong opioids; however, the starting point depends on careful assessment of pain severity. Pain associated with some conditions may respond differently to treatment. A recent Cochrane review indicated with moderate quality evidence that tramadol, alone or in combination with paracetamol or NSAIDs, does not have an important effect on pain or physical function in moderateto-severe osteoarthritis of the knee or hip [54]. Thus, in this setting, an appropriate level 1 treatment might start with an anti-inflammatory plus a more potent analgesic combination (Fig. 4).

\section{CONCLUSIONS}

Recent developments in pain pathophysiology are changing the pharmacological approach to pain management. The possibility of identifying the pain generators and the pathogenetic mechanisms of pain can inform the rational choice of appropriate drugs. A properly conducted clinical examination can distinguish between nociceptive, neuropathic, and mixed pain. The Italian Society of General Medicine and Primary Care (SIMG) has developed an algorithm for identifying the pathogenetic mechanisms of pain [7]. The multimodal therapy approach described in this article aims to control each of the pain mechanisms identified. This is achieved through the appropriate use, when indicated, of drugs that act peripherally on nociceptors (NSAIDs and corticosteroids), at the level of nerve fibers (sodium channel inhibitors) or at the synaptic level (paracetamol, opiates, $\alpha-2 \delta$ ligands, antidepressants, acetyl-Lcarnitine). 

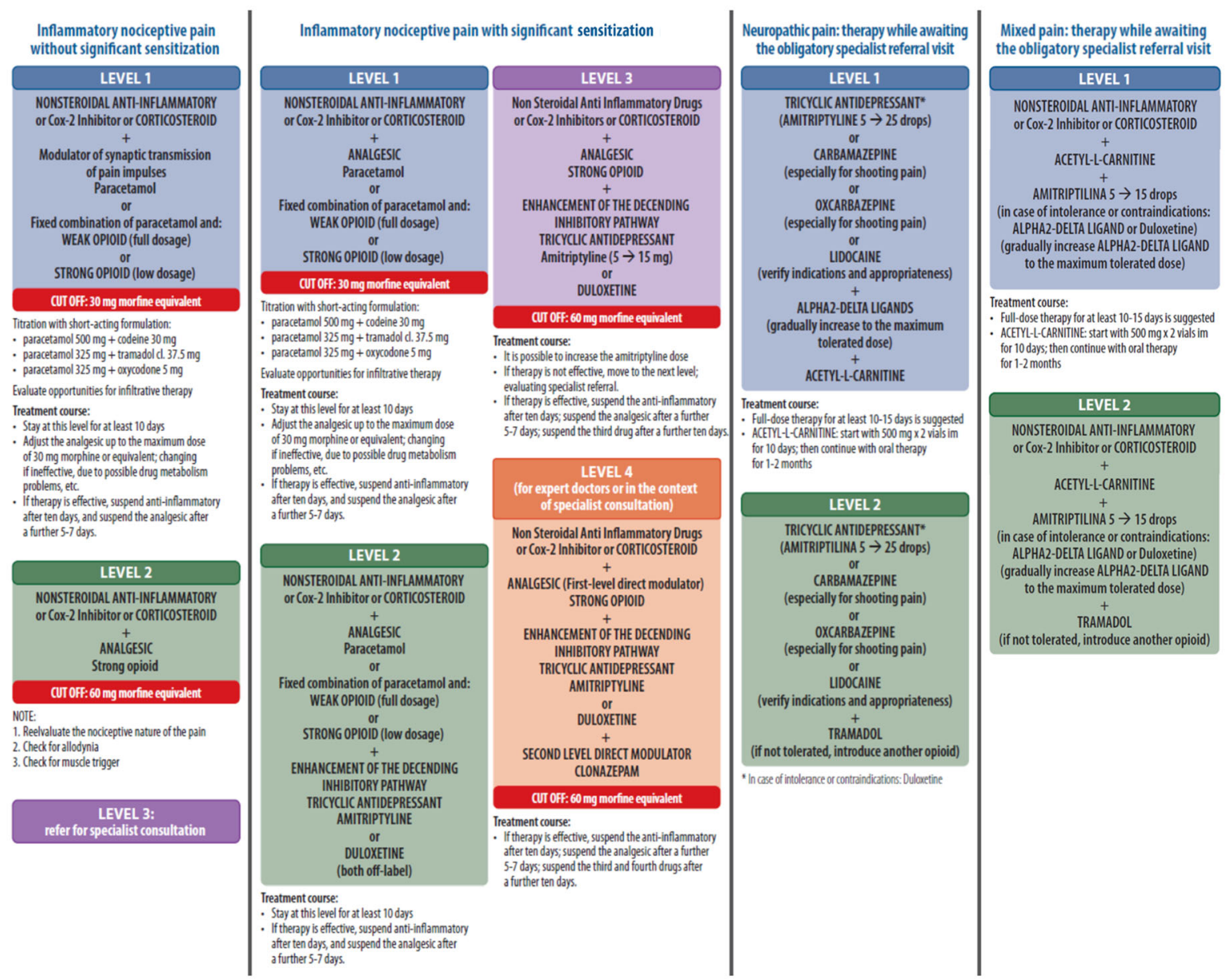

Fig. 4 Step-by step treatment strategies according to chronic pain type

\section{ACKNOWLEDGEMENTS}

Funding. Sponsorship for the Rapid Service Fee was funded by Alfasigma, Italy.

Editorial assistance. Editorial assistance in the preparation of this article was provided by Richard Vernell, an independent medical writer, on behalf of Springer Healthcare, Italy. This support was funded by Alfasigma, Italy.

Authorship. All named authors meet the International Committee of Medical Journal Editors (ICMJE) criteria for authorship for this article, take responsibility for the integrity of the work as a whole, and have given their approval for this version to be published.
Disclosures. Diego Fornasari declared relationships during the past 2 years as conference speaker, member of advisory boards or consultants for the following companies: Abiogen, Alfasigma, Astellas, Bayer, Grünenthal, Indena, Molteni, Scharper, SPA, Zambon. Alberto Magni declares relationships with Angelini, Alfasigma, Ibsa Farmaceutici, Grünenthal and Pfizer. Cesare Bonezzi, Claudio Cricelli and Giuseppe Ventriglia have nothing to disclose.

Compliance with Ethics Guidelines. This article is based on previously conducted studies and does not contain any new studies with human participants or animals performed by any of the authors. 
Open Access. This article is licensed under a Creative Commons Attribution-NonCommercial 4.0 International License, which permits any non-commercial use, sharing, adaptation, distribution and reproduction in any medium or format, as long as you give appropriate credit to the original author(s) and the source, provide a link to the Creative Commons licence, and indicate if changes were made. The images or other third party material in this article are included in the article's Creative Commons licence, unless indicated otherwise in a credit line to the material. If material is not included in the article's Creative Commons licence and your intended use is not permitted by statutory regulation or exceeds the permitted use, you will need to obtain permission directly from the copyright holder. To view a copy of this licence, visit http://creativecommons.org/licenses/by$\mathrm{nc} / 4.0 /$.

\section{REFERENCES}

1. Hansen AB, Skurtveit S, Borchgrevink PC, et al. Consumption of and satisfaction with health care among opioid users with chronic non-malignant pain. Acta Anaesthesiol Scand. 2015;59(10): 1355-66.

2. Romanelli RJ, Shah SN, Ikeda L, et al. Patient characteristics and healthcare utilization of a chronic pain population within an integrated healthcare system. Am J Manag Care. 2017;23(2): e50-6.

3. Nijs J, Torres-Cueco R, van Wilgen CP, et al. Applying modern pain neuroscience in clinical practice: criteria for the classification of central sensitization pain. Pain Phys. 2014;17(5):447-57.

4. Fishman SM, Young HM, Lucas Arwood E, et al. Core competencies for pain management: results of an interprofessional consensus summit. Pain Med. 2013;14(7):971-81.

5. Briggs EV, Battelli D, Gordon D, et al. Current pain education within undergraduate medical studies across Europe: advancing the provision of pain education and learning (APPEAL) study. BMJ Open. 2015;5(8):e006984.

6. Shipton EE, Bate F, Garrick R, Steketee C, Shipton EA, Visser EJ. Systematic review of pain medicine content, teaching, and assessment in medical school curricula internationally. Pain Ther. 2018;7(2):139-61.

7. Bonezzi C, Fornasari D, Cricelli C, Magni A, Ventriglia G. Not all pain is created equal: basic definitions and diagnostic work-up. Pain Ther. 2020. https://doi.org/10.1007/s40122-020-00217-w.

8. Smoak KA, Cidlowski JA. Mechanisms of glucocorticoid receptor signaling during inflammation. Mech Ageing Dev. 2004;125(10-11):697-706.

9. Topper JN, Cai J, Falb D, Gimbrone MA Jr. Identification of vascular endothelial genes differentially responsive to fluid mechanical stimuli: cyclooxygenase-2, manganese superoxide dismutase, and endothelial cell nitric oxide synthase are selectively up-regulated by steady laminar shear stress. Proc Natl Acad Sci USA. 1996;93(19):10417-22.

10. Patrignani P, Patrono C. Cyclooxygenase inhibitors: from pharmacology to clinical read-outs. Biochim Biophys Acta. 2015;1851(4):422-32.

11. da Costa BR, Reichenbach S, Keller N, et al. Effectiveness of non-steroidal anti-inflammatory drugs for the treatment of pain in knee and hip osteoarthritis: a network meta-analysis. Lancet. 2017;390(10090):e21-33.

12. Baron R. Neuropathic pain: a clinical perspective. Handb Exp Pharmacol. 2009;194:3-30.

13. Levinson SR, Luo S, Henry MA. The role of sodium channels in chronic pain. Muscle Nerve. 2012;46(2):155-65.

14. Demant DT, Lund K, Vollert J, et al. The effect of oxcarbazepine in peripheral neuropathic pain depends on pain phenotype: a randomised, doubleblind, placebo-controlled phenotype-stratified study. Pain. 2014;155(11):2263-73.

15. Fillingim RB, Loeser JD, Baron R, Edwards RR. Assessment of chronic pain: domains, methods, and mechanisms. J Pain. 2016;17(9 Suppl):T10-20.

16. Tan T, Barry P, Reken S, Baker M, Guideline Development Group. Pharmacological management of neuropathic pain in non-specialist settings: summary of NICE guidance. BMJ. 2010;340:1079.

17. Thomas AM, Atkinson TJ. Old friends with new faces: are sodium channel blockers the future of adjunct pain medication management? J Pain. 2018;19(1):1-9.

18. Davies PS, Galer BS. Review of lidocaine patch 5\% studies in the treatment of postherpetic neuralgia. Drugs. 2004;64(9):937-47. 
19. Arikkath J, Campbell KP. Auxiliary subunits: essential components of the voltage-gated calcium channel complex. Curr Opin Neurobiol. 2003;13(3):298-307.

20. Hendrich J, Van Minh AT, Heblich F, et al. Pharmacological disruption of calcium channel trafficking by the alpha2delta ligand gabapentin. Proc Natl Acad Sci USA. 2008;105(9):3628-33.

21. Bauer CS, Nieto-Rostro M, Rahman W, et al. The increased trafficking of the calcium channel subunit alpha2delta-1 to presynaptic terminals in neuropathic pain is inhibited by the alpha2delta ligand pregabalin. J Neurosci. 2009;29(13):4076-88.

22. U.S. Food and Drug Administration. Drug Safety Communications. FDA warns about serious breathing problems with seizure and nerve pain medicines gabapentin (Neurontin, Gralise, Horizant) and pregabalin (Lyrica, Lyrica CR). 2019. https://www.fda.gov/drugs/drug-safety-andavailability/fda-warns-about-serious-breathingproblems-seizure-and-nerve-pain-medicinesgabapentin-neurontin. Accessed 22 Dec 2019.

23. Domon $\mathrm{Y}$, Arakawa $\mathrm{N}$, Inoue $\mathrm{T}$, et al. Binding characteristics and analgesic effects of mirogabalin, a novel ligand for the $\alpha(2) \delta$ subunit of voltage-gated calcium channels. J Pharmacol Exp Ther. 2018;365(3):573-82.

24. Sharma CV, Long JH, Shah S, et al. First evidence of the conversion of paracetamol to AM404 in human cerebrospinal fluid. J Pain Res. 2017;10:2703-9.

25. Singla NK, Parulan C, Samson R, et al. Plasma and cerebrospinal fluid pharmacokinetic parameters after single-dose administration of intravenous, oral, or rectal acetaminophen. Pain Pract. 2012;12(7):523-32.

26. Apfel CC, Turan A, Souza K, Pergolizzi J, Hornuss C. Intravenous acetaminophen reduces postoperative nausea and vomiting: a systematic review and meta-analysis. Pain. 2013;154(5):677-89.

27. Besson M, Matthey A, Daali Y, et al. GABAergic modulation in central sensitization in humans: a randomized placebo-controlled pharmacokineticpharmacodynamic study comparing clobazam with clonazepam in healthy volunteers. Pain. 2015;156(3):397-404.

28. Al-Hasani R, Bruchas MR. Molecular mechanisms of opioid receptor-dependent signaling and behavior. Anesthesiology. 2011;115(6):1363-81.

29. Stevens EB, Stephens GJ. Recent advances in targeting ion channels to treat chronic pain. $\mathrm{Br} \mathrm{J}$ Pharmacol. 2018;175(12):2133-7.
30. Dowell D, Haegerich TM, Chou R. CDC guideline for prescribing opioids for chronic pain-Checklist for prescribing opioids for chronic pain. 2016. MMWR Recomm Rep 2016;65(No. RR-1):1-49. https://stacks.cdc.gov/view/cdc/38025.

31. Hayhurst CJ, Durieux ME. Differential opioid tolerance and opioid-induced hyperalgesia: a clinical reality. Anesthesiology. 2016;124(2):483-8.

32. St Sauver JL, Olson JE, Roger VL, et al. CYP2D6 phenotypes are associated with adverse outcomes related to opioid medications. Pharmgenomics Pers Med. 2017;10:217-27.

33. Morlion BJ, Mueller-Lissner SA, Vellucci R, et al. Oral prolonged-release oxycodone/naloxone for managing pain and opioid-induced constipation: a review of the evidence. Pain Pract. 2018;18(5): 647-65.

34. Nossaman VE, Ramadhyani U, Kadowitz PJ, Nossaman BD. Advances in perioperative pain management: use of medications with dual analgesic mechanisms, tramadol \& tapentadol. Anesthesiol Clin. 2010;28(4):647-66.

35. Grond S, Sablotzki A. Clinical pharmacology of tramadol. Clin Pharmacokinet. 2004;43(13): 879-923.

36. Tzschentke TM, Jahnel U, Kogel B, et al. Tapentadol hydrochloride: a next-generation, centrally acting analgesic with two mechanisms of action in a single molecule. Drugs Today (Barc). 2009;45(7):483-96.

37. Marinangeli F, Evangelista M, Finco G. Tapentadol prolonged release in the treatment of musculoskeletal pain: an innovative pharmacological option. Eur Rev Med Pharmacol Sci. 2019;23(4 Suppl):5-13.

38. Finnerup NB, Attal N, Haroutounian S, et al. Pharmacotherapy for neuropathic pain in adults: a systematic review and meta-analysis. Lancet Neurol. 2015;14(2):162-73.

39. Hayashida KI, Obata H. Strategies to treat chronic pain and strengthen impaired descending noradrenergic inhibitory system. Int $\mathrm{J}$ Mol Sci. 2019;20(4):822.

40. Ito S, Suto T, Saito S, Obata H. Repeated administration of duloxetine suppresses neuropathic pain by accumulating effects of noradrenaline in the spinal cord. Anesth Analg. 2018;126(1):298-307.

41. Mazzitelli M, Palazzo E, Maione S, Neugebauer V. Group II metabotropic glutamate receptors: role in pain mechanisms and pain modulation. Front Mol Neurosci. 2018;11:383. 
42. Pereira V, Goudet C. Emerging trends in pain modulation by metabotropic glutamate receptors. Front Mol Neurosci. 2019;11:464.

43. Rebouche CJ. Kinetics, pharmacokinetics, and regulation of L-carnitine and acetyl-L-carnitine metabolism. Ann N Y Acad Sci. 2004;1033:30-41.

44. Di Stefano G, Di Lionardo A, Galosi E, Truini A, Cruccu G. Acetyl-L-carnitine in painful peripheral neuropathy: a systematic review. J Pain Res. 2019;12:1341-51.

45. Kweon HJ, Suh BC. Acid-sensing ion channels (ASICs): therapeutic targets for neurological diseases and their regulation. BMB Rep. 2013;46: 295-304.

46. Barbero M, Schneebeli A, Koetsier E, Maino P. Myofascial pain syndrome and trigger points: evaluation and treatment in patients with musculoskeletal pain. Curr Opin Support Palliat Care. 2019;13:270-6.

47. Abdel Shaheed C, Maher CG, Williams KA, McLachlan AJ. Efficacy and tolerability of muscle relaxants for low back pain: systematic review and meta-analysis. Eur J Pain. 2017;21:228-37.

48. Qaseem A, Wilt TJ, McLean RM, Forciea MA, Clinical Guidelines Committee of the American College of Physicians. Noninvasive treatments for acute, subacute, and chronic low back pain: a clinical practice guideline from the American College of Physicians. Ann Intern Med. 2017;166:514-30.

49. Ghanavatian S, Derian A. Tizanidine. In: StatPearls [Internet]. Treasure Island (FL): StatPearls Publishing; 2020. https://www.ncbi.nlm.nih.gov/books/ NBK519505/. Accessed 1 Oct 2019

50. Rossi M, Ianigro G, Liberatoscioli G, et al. Eperisone versus tizanidine for treatment of chronic low back pain. Minerva Med. 2012;103:143-9.

51. Carta M, Murru L, Botta P, et al. The muscle relaxant thiocolchicoside is an antagonist of GABAA receptor function in the central nervous system. Neuropharmacology. 2006;51:805-15.

52. Thiocolchicoside: review of adverse effects. Prescrire Int. 2016;25:41-3.

53. European Medicines Agency. European Medicines Agency recommends restricting use of thiocolchicoside by mouth or injection. EMA/40615/ 2014. https://www.ema.europa.eu/en/documents/ referral/article-31-referral-european-medicines-age ncy-recommends-restricting-use-thiocolchicosidemouth_en.pdf. Accessed 20 June 2020.

54. Toupin April K, Bisaillon J, Welch V, et al. Tramadol for osteoarthritis. Cochrane database Syst Rev. 2019;5(5):CD005522. 